\title{
Proliposomes for oral delivery of dehydrosilymarin: preparation and evaluation in vitro and in vivo
}

\author{
Chang CHU, Shan-shan TONG, Ying XU, Li WANG, Min FU, Yan-ru GE, Jiang-nan YU*, Xi-ming XU* \\ Department of Pharmaceutics, School of Pharmacy, Jiangsu University, Zhenjiang 212013, China
}

\begin{abstract}
Aim: To formulate proliposomes with a polyphase dispersed system composed of soybean phospholipids, cholesterol, isopropyl myristate and sodium cholate to improve the oral bioavailability of dehydrosilymarin, an oxidized form of herbal drug silymarin. Methods: Dehydrosilymarin was synthesized from air oxidation of silymarin in the presence of pyridine, and proliposomes were prepared by a film dispersion-freeze drying method. Morphological characterization of proliposomes was observed using a transmission electron microscope. Particle size and encapsulation efficiency of proliposomes were measured. The in vitro release of dehydrosilymarin from suspension and proliposomes was evaluated. The oral bioavailability of dehydrosilymarin suspension and proliposomes was investigated in rabbits.

Results: The proliposomes prepared under the optimum conditions were spherical and smooth with a mean particle size in the range of 7 to $50 \mathrm{~nm}$. Encapsulation efficiency was $81.59 \% \pm 0.24 \%$. The in vitro accumulative release percent of dehydrosilymarinloaded proliposomes was stable, which was slow in $\mathrm{pH} 1.2$, and increased continuously in $\mathrm{pH} 6.8$, and finally reached $86.41 \%$ at $12 \mathrm{~h}$. After oral administration in rabbits, the relative bioavailability of proliposomes versus suspension in rabbits was $228.85 \%$.

Conclusion: Proliposomes may be a useful vehicle for oral delivery of dehydrosilymarin, a drug poorly soluble in water.
\end{abstract}

Keywords: silymarin; dehydrosilymarin; proliposomes; oral bioavailability; pharmacokinetics

Acta Pharmacologica Sinica (2011) 32: 973-980; doi: 10.1038/aps.2011.25; published online 13 Jun 2011

\section{Introduction}

Milk thistle (Silybum marianum) is one of the few herbal drugs whose excellent pharmacological profile readily lends itself to proof of clinical efficacy ${ }^{[1]}$. Silymarin, the seed extract of milk thistle, has been widely used to maintain liver health and treat liver disorders ${ }^{[2]}$. Different dosage forms of silymarin have been reported ${ }^{[3,4]}$.

Dehydrosilymarin is a novel compound synthesized from silymarin, exhibited markedly greater pharmacological activity in comparison with silymarin. Nevertheless, the poor water-solubility of dehydrosilymarin hindered the effectiveness of dehydrosilymarin compared to silymarin ${ }^{[5]}$.

Recently, great interest has been shown in the use of liposomes for improving oral absorption and bioavailability of hydrophobic drugs ${ }^{[6]}$. Liposomes are enclosed vesicles composed of phosphatidylcholine and cholesterol lipid bilayers, which have been extensively studied as drug carriers ${ }^{[7,8]}$. The similarity between liposomal lipid bilayers and biomembranes

\footnotetext{
* To whom correspondence should be addressed.

E-mail xuxm@ujs.edu.cn (Xi-ming XU); yjn@ujs.edu.cn (Jiang-nan YU)

Received 2010-12-09 Accepted 2011-03-01
}

and the relatively small size of liposomes significantly facilitate their oral absorption ${ }^{[9]}$. However, liposomes still lack a significant medical impact despite a relatively long history of investigation. Limited physical and biological stability are the major barriers in their development, such as with aggregation, sedimentation, fusion, phospholipid hydrolysis and/or oxidation $^{[4]}$. Accordingly, the development of stable liposomes is a prerequisite for their exploitation in the delivery of therapeutic drugs ${ }^{[10,11]}$. For many years, attempts have been made to improve the stability of liposomes by several methods, including preparing more stable bilayers ${ }^{[12]}$, coating their surface with protecting polymers ${ }^{[13-16]}$, and modifying charge ${ }^{[17-19]}$.

Proliposomes are defined as dry, free-flowing particles with a dispersed system that can immediately form a liposomal suspension when in contact with water. Compared with conventional liposomes, proliposomes exhibit more advantages in promoting drug absorption. Because of their solid properties, the physical stability of liposomes can be improved upon without influencing their intrinsic characteristics. Therefore, proliposomes would be a potential vehicle to help improve the oral absorption of hydrophobic drugs. The underlying mechanism allowing proliposomes to improve oral absorption might be partially explained by the presence of bile salts, which can 
interact with phospholipids in the gastrointestinal tract to form mixed micelles for vehicles/mesophases to increase the solubility of hydrophobic drugs ${ }^{[20,21]}$.

Expanding on our previous work ${ }^{[5]}$, novel proliposomes (a polyphase dispersed system containing trace micelles and emulsions) loaded with dehydrosilymarin were prepared. The physicochemical characteristics and in vitro release characteristics of dehydrosilymarin treatment were evaluated. Furthermore, the oral absorption of the dehydrosilymarin suspension and dehydrosilymarin-loaded proliposomes was investigated and compared in rabbits.

\section{Materials and methods Materials}

Silymarin was kindly provided by Zhongxing Pharmaceutical Co Ltd (Jiangsu, China). Soybean phospholipid, which contained approximately $82 \%(w / w)$ phosphatidylcholine, was purchased from Taiwei Co Ltd (Shanghai, China). Cholesterol was supplied by Shanghai Chemical Reagent Co (Shanghai, China). Sodium cholate was obtained from Sigma Chemical Co (USA). Isopropyl myristate and all other reagents were from Sinopharm Chemical Reagent Co Ltd (Shanghai, China). Other chemical reagents were of analytical grade or better.

\section{Synthesis of dehydrosilymarin}

Dehydrosilymarin was prepared essentially according to a reported method ${ }^{[22]}$, which was originally designed for the preparation of dehydrosilybin. In brief, silymarin was dissolved in pyridine and heated to $90{ }^{\circ} \mathrm{C}$ under reflux for $77 \mathrm{~h}$ with stirring. After the reaction, pyridine was removed using a rotary evaporator. To remove the residual pyridine, toluene was introduced and evaporated. The remaining pellet was dissolved in ethyl acetate, loaded onto a silica gel column, and then eluted with hot acetone. After those procedures, acetone was removed from the products with distillation. The remaining pellet was re-dissolved in hot ethanol and filtered through a Double-ring \#102 filter paper (Xinhua Paper Industry Co Ltd, Hangzhou, China). The pass-through fraction was air dried until approximately $4 \mathrm{~g}$ of brown dehydrosilymarin pellet was obtained. Dehydrosilymarin's structure was verified by IR and NMR, which were consistent with the results reported in the literature ${ }^{[23]}$ (spectra not shown).

\section{Preparation of dehydrosilymarin-loaded proliposomes}

Dehydrosilymarin-loaded proliposomes were prepared by the film dispersion-freeze drying method. Dehydrosilymarin $(0.1 \mathrm{~g})$ and phospholipids (0.3 g) were dissolved in acetone solution and heated to $40{ }^{\circ} \mathrm{C}$ under reflux in a water bath for at least $3 \mathrm{~h}$ with stirring. After the organic solvent was evaporated off using a rotary evaporator (Heidolph Co, Germany) under vacuum, a thin film was formed on the wall of the flask. The film was dissolved with ethanol after $0.075 \mathrm{~g}$ cholesterol, $0.2 \mathrm{~g}$ isopropyl myristate (IPM) and $0.2 \mathrm{~g}$ sodium cholate were added with ultrasound conditions. The solution was then completely evaporated, and the dried residues were gathered and transferred into a petri dish. Distilled water $(10 \mathrm{~mL})$ containing 5\% mannitol was added to produce the liposomal suspension at room temperature. After freezing at $-80{ }^{\circ} \mathrm{C}$ for $2 \mathrm{~h}$ and drying under vacuum for $24 \mathrm{~h}$ (Alpha 2-4, CHRIST, Germany), the yellow dehydrosilymarin-loaded proliposome powder was produced.

\section{Characteristics of dehydrosilymarin-loaded proliposomes Morphological characterization}

The morphology of dehydrosilymarin-loaded proliposomes was observed by transmission electron microscope (TEM) (JEM-2100, JEOL, Japan). The formulation was diluted with distilled water and shaken thoroughly to obtain liposomal dispersion. A $2 \mu \mathrm{L}$ drop of suspension was placed on a carboncoated copper grid and dried in bright light until a thin liquid film formed on one side. This sheet of copper with stained film was set onto the end of a long iron bar and inserted into the TEM for sample viewing and photography.

\section{Particle size measurement}

A certain amount of dehydrosilymarin-loaded proliposomes was diluted with distilled water to form liposomes. The particle size of the so-formed liposomal suspension was measured using Zetasizer 3000 (Malvern, UK).

\section{Determination of entrapment efficiency}

Determination of the content of dehydrosilymarin in dehydrosilymarin-loaded proliposomes

The content of dehydrosilymarin in dehydrosilymarin-loaded proliposomes was determined as follows. A measured number of dehydrosilymarin-loaded proliposomes $(0.2 \mathrm{~g})$ were hydrated with $100 \mathrm{~mL}$ of distilled water. The obtained liposomal suspension $(1 \mathrm{~mL})$ was mixed with anhydrous alcohol $(9 \mathrm{~mL})$ and analyzed with a UV-spectrophotometer (UV2401, Shimazu, Japan) at $255 \mathrm{~nm}$, the maximum absorption wavelength of dehydrosilymarin. Blank liposome, with an absorption maximum about $208 \mathrm{~nm}$, did not interfere with drug detection. The concentration of dehydrosilymarin can be mathematically calculated with the standard curve.

\section{Determination of entrapment efficiency of dehydrosilymarin- loaded proliposomes}

The percentage of drug entrapped within the proliposomes was measured according to the method described by $\mathrm{Xiao}^{[4]}$. A suitable quantity of proliposomes loaded with $0.1 \mathrm{~g}$ dehydrosilymarin was reconstituted with $100 \mathrm{~mL}$ of distilled water. The percentage of dehydrosilymarin encapsulated into proliposomes was measured after separating free drug from dehydrosilymarin-loaded proliposomes with $0.22 \mu \mathrm{m}$ cellulose nitrate membrane. Because dehydrosilymarin is slightly soluble in water, after dispersing the proliposomes with water, non-trapped dehydrosilymarin was filtrated via cellulose nitrate membrane. The encapsulation efficiency (EE\%) of dehydrosilymarin in the reconstituted liposomes was calculated with the following formula:

$$
\mathrm{EE} \%=\mathrm{C}_{\mathrm{a}} / \mathrm{C}_{\mathrm{b}} \times 100 \%
$$

where $C_{a}$ and $C_{b}$ denote the concentration of dehydrosilymarin 
in the reconstituted liposomes after (a) and before filtration (b).

\section{In vitro release studies}

The in vitro release studies were conducted according to the release test method described by China Pharmacopoeia (2010 edition, paddle method) with minor modifications. Briefly, proliposomes entrapping $0.1 \mathrm{~g}$ dehydrosilymarin were instilled into a dialysis bag (MWCO $3500 \mathrm{D}, 25 \mathrm{~mm} \times 5 \mathrm{~m}$, Shanghai Green Bird Science and Technology Development, China) after exposure to distilled water. Dialysis bags were fixed on the paddles before immersion into the dissolution medium (pH $1.2 \mathrm{HCl}, 900 \mathrm{~mL}$; pH 6.8 phosphate buffered saline, $900 \mathrm{~mL}$ ) containing $0.1 \%$ sodium dodecyl sulfate as a surfactant (sink condition). The entire set was placed on a dissolution tester (ZRS-8G, Tianjin University Radio Power Station, China) set to a constant speed of 100 revolutions per minute at $37^{\circ} \mathrm{C}$. At different time intervals, $10 \mathrm{~mL}$ samples were withdrawn and filtered using $0.22 \mu \mathrm{m}$ cellulose nitrate membranes, and $10 \mathrm{~mL}$ of fresh medium was supplemented into the beaker. The samples were measured spectrophotometrically at $255 \mathrm{~nm}$.

\section{Determination of dehydrosilymarin in rabbit plasma by RP-HPLC} In our study, the plasma concentrations of dehydrosilymarin were determined by a HPLC-UV method. Dehydrosilymarin was separated at $25^{\circ} \mathrm{C}$ by a $\mathrm{C}_{18}$ column (VP-ODS, $150 \mathrm{~mm} \times 4.6 \mathrm{~mm}, 5 \mu \mathrm{m}$, Shimazu, Japan) and analyzed at 255 $\mathrm{nm}$. The mobile phase was composed of methanol/double distilled water/methanoic acid in a volume ratio of 57/43/0.2 $(v / v / v)$ at a flow rate of $1.2 \mathrm{~mL} / \mathrm{min}$.

After plasma samples had been thawed, dehydrosilymarin in rabbit plasma was extracted by liquid-liquid extraction procedures as follows: $200 \mu \mathrm{L}$ of rabbit plasma was added to a $10 \mathrm{~mL}$ polypropylene screw-capped conical tube, which was followed by the addition of $20 \mu \mathrm{L}$ of internal standard solution (a-naphthol, $100 \mu \mathrm{g} / \mathrm{mL}$ in methanol), $20 \mu \mathrm{L}$ of methanol, 50 $\mu \mathrm{L}$ of a $0.5 \mathrm{~mol} / \mathrm{L} \mathrm{K}_{2} \mathrm{HPO}_{4}$ solution and $5 \mathrm{~mL}$ of anhydrous diethyl ether, in order. After vortexing for $2 \mathrm{~min}$, the mixture was centrifuged at 3000 revolutions per minute (Clements GS 200 centrifuge) for $10 \mathrm{~min}$. The organic layer was transferred to another tube and evaporated under a light stream of nitrogen at $37^{\circ} \mathrm{C}$. The residues were re-suspended in 200 $\mu \mathrm{L}$ of mobile phase and vortexed for $30 \mathrm{~s}$. Aliquots $(20 \mu \mathrm{L})$ of the supernatant were injected for HPLC analysis. Quantitation was based on the peak area ratio $\left(\mathrm{A}_{\mathrm{DSLY}} / \mathrm{A}_{\mathrm{IS}}\right)$. Linearity was observed over the concentration range of $0.22-55 \mu \mathrm{g} /$ $\mathrm{mL}$. Moreover, the limit of detection $(\mathrm{S} / \mathrm{N} \geq 3)$, within-day and between-day precisions, and recovery method of dehydrosilybin in rabbit plasma were also determined by HPLC.

\section{Bioavailability studies}

The bioavailability of dehydrosilymarin-loaded proliposomes was compared with that of dehydrosilymarin suspension. Dehydrosilymarin-loaded proliposomes were diluted with distilled water to form liposomal suspension, while a dehy- drosilymarin suspension was prepared by dispersing the milling drug in water by ultrasonic resuspension. Six rabbits weighing $2.5 \pm 0.5 \mathrm{~kg}$ (supplied by the Laboratory Animal Center of Jiangsu University) were randomly divided into two groups and fasted overnight prior to the experiment, while water was available ad libitum following the regulations for the administration of affairs concerning experimental animals (State Council of the China, 1988). All research protocols were approved by the Research Ethics Committee of Jiangsu University. The rabbits in each group were given the dehydrosilymarin liposomal suspension and dehydrosilymarin suspension through gavage administration for a dose of dehydrosilymarin of $80 \mathrm{mg} / \mathrm{kg}$. Approximately $1.2 \mathrm{~mL}$ of blood was collected through the peripheral ear vein into heparinized tubes at $0.25,0.5,1,2,3,4,6,8,10$, and $12 \mathrm{~h}$. Blood samples were immediately separated by centrifugation (3000 revolutions per minute for $10 \mathrm{~min}$ ), and subsequent plasma samples were stored at $-20^{\circ} \mathrm{C}$ until further analysis.

The peak concentration $\left(C_{\max }\right)$ and peak time $\left(t_{\max }\right)$ were derived directly from the experimental points as raw data. The other pharmacokinetic parameters were calculated by the software program BAPP 2.3 (Nanjing Baikang Pharmaceutical Co Ltd, China).

\section{Results}

\section{Synthesis of dehydrosilymarin}

The experimental results demonstrated that reaction time and reaction temperature could affect the synthetic product. Too long a reaction time or too high a reaction temperature would result in carbonation. Finally, dehydrosilymarin was prepared at $90{ }^{\circ} \mathrm{C}$ under reflux for $77 \mathrm{~h}$ with stirring. The yield of dehydrosilymarin was generally approximately $70 \%-80 \%$.

\section{Preparation of dehydrosilymarin-loaded proliposomes}

The shape, outward appearance and entrapment efficiency of proliposomes were characterized. The results proved that the proliposomes was smooth and spherieal in appearance with better dispersion and high entrapment efficiency. The proliposomes can be administered orally in the form of powders or filled into capsules.

\section{Characteristics of dehydrosilymarin in dehydrosilymarin-loaded proliposomes}

The dehydrosilymarin-loaded proliposomes turned into a liposomal suspension when diluted with distilled water. The morphological characterization of dried dehydrosilymarinloaded liposomes is shown in Figure 1. The observed liposome droplets were spherical.

Because the particle size of the preparation made a large impact on its in vitro and in vivo performance, we measured the size distribution of dehydrosilymarin-loaded proliposomes after diluting them with distilled water. The result is displayed in Figure 2. It can be seen from the picture that the particle size of dehydrosilymarin-loaded liposomes was distributed in the range of 7 to $50 \mathrm{~nm}$, and the average diameter was $15.5 \mathrm{~nm}$, which was consistent with the results of the TEM 


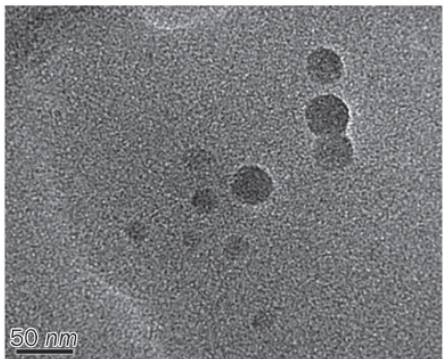

Figure 1. Transmission electron micrograph for liposomal dispersion at $\times 4000$ magnification.

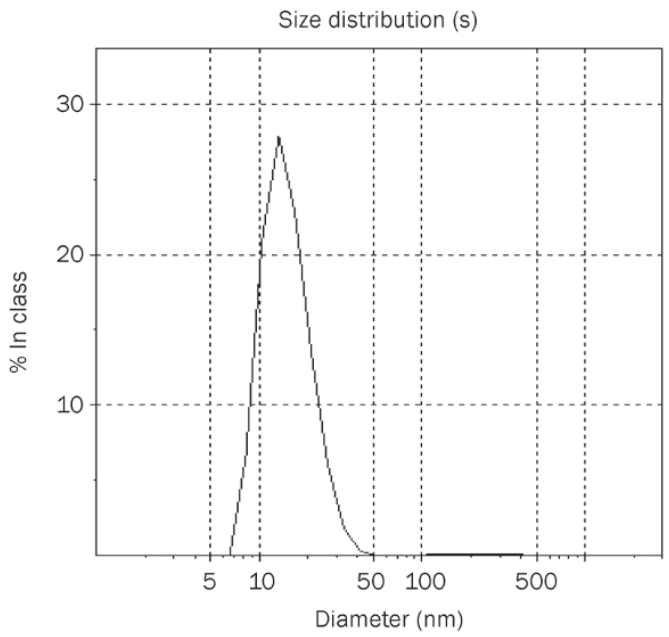

Figure 2. Size distribution of dehydrosilymarin-loaded proliposomes.

analysis. We were pleased to note that the relatively small size of liposomes may have the potential to facilitate the oral absorption of dehydrosilymarin.

The content of dehydrosilymarin in dehydrosilymarinloaded proliposomes after hydration with water was $25.00 \pm 5.93 \mu \mathrm{g} / \mathrm{mL}(n=3)$, and the drug loading percentage was approximately $12.5 \%$.

The entrapment efficiency of dehydrosilymarin in proliposomes was $81.59 \% \pm 0.24 \%(n=3)$, which was predominately dependent on the dehydrosilymarin/phospholipid ratio and sodium cholate/phospholipid. Increasing the amount of phospholipid in addition to adding a moderate amount of surfactants in the prescription can increase drug encapsulation efficiency. However, excessive amounts of phospholipid not only increased the viscosity of the final preparation, but also yielded a sharp reduction in the drug loading efficiency, while the toxicity of surfactant also limited its dosage.

\section{In vitro release studies}

As shown in Figure 3, the release of dehydrosilymarin from suspension and proliposomes was poor in $\mathrm{pH} 1.2$, with less than $20 \%$ of drug going into the medium after $12 \mathrm{~h}$. Despite a slightly higher release of the drug from suspension than from

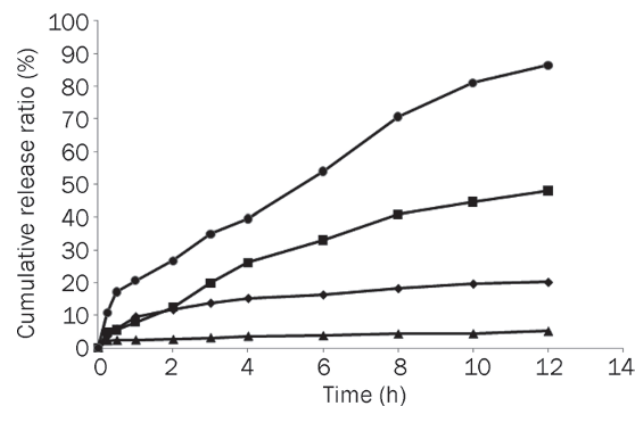

Figure 3. In vitro release profiles of dehydrosilymarin from suspension and proliposomes in different release mediums containing $0.1 \%$ of sodium dodecyl sulfate as surfactant. ( ), suspension in $900 \mathrm{~mL} \mathrm{HCl}$ (pH 1.2); ( $\mathbf{\Delta})$, proliposomes in $900 \mathrm{~mL} \mathrm{HCl} \mathrm{(pH} \mathrm{1.2);} \mathrm{( \bullet ),} \mathrm{suspension} \mathrm{in}$ $900 \mathrm{~mL}$ phosphate buffered saline $(\mathrm{pH} 6.8)$; $(\bullet)$, proliposomes in $900 \mathrm{~mL}$ phosphate buffered saline ( $\mathrm{pH} 6.8)$.

proliposomes in $\mathrm{pH} 1.2$, the release of the drug from proliposomes was tremendously increased compared with that of the drug suspension in $\mathrm{pH}$ 6.8. Furthermore, dehydrosilymarin was continuously released from proliposomes in PBS, and the cumulative release ratio was up to $86.41 \%$ at $12 \mathrm{~h}$.

\section{Rabbit bioavailability experiments}

Dehydrosilybin, the main active ingredient of dehydrosilymarin, was measured as the indicator of bioavailability. In accordance with previous pretreatment and chromatographic conditions, blank rabbit plasma, blank rabbit plasma spiked with dehydrosilybin and a sample after oral administration of dehydrosilymarin-loaded proliposomes were analyzed by HPLC (Figure 4). Good separation of the main peak and the hybridized peak was achieved in the present chromatographic conditions. The retention time of internal standard and dehydrosilybin was approximately 7.5 and $17.5 \mathrm{~min}$, respectively.

Within the concentration range of $0.22-55 \mu \mathrm{g} / \mathrm{mL}$, the peak area ratio $(\mathrm{R})$ of dehydrosilybin as a whole compared to the internal standard correlated well to the spiked plasma concentration: $R=0.5691 \mathrm{C}-0.0058, r=0.9991$. The lowest limit of quantification for the determination of dehydrosilybin in rabbit plasma was found to be $50 \mathrm{ng} / \mathrm{mL}$. The relative standard deviations of intra-day and inter-day assay and the spiked recoveries of dehydrosilybin from rabbit plasma are shown in Table 1.

The oral bioavailabilities of dehydrosilymarin-loaded proliposomes and drug powders were compared in rabbits. Figure 5 shows the drug plasma profiles after gavage administration of dehydrosilymarin-loaded liposomal suspension and dehydrosilymarin suspension $(n=3)$. The liposomal suspension was obtained by dispersing proliposome powders in distilled water. The dehydrosilymarin suspension was prepared by mixing dehydrosilymarin powders with distilled water. As seen in the graph, the plasma concentration of dehydrosilymarin suspension was at a low and stable level at $12 \mathrm{~h}$, although a slight peak was observed at $2 \mathrm{~h}$. The drug concentration of dehydrosilymarin-loaded liposomal suspension 

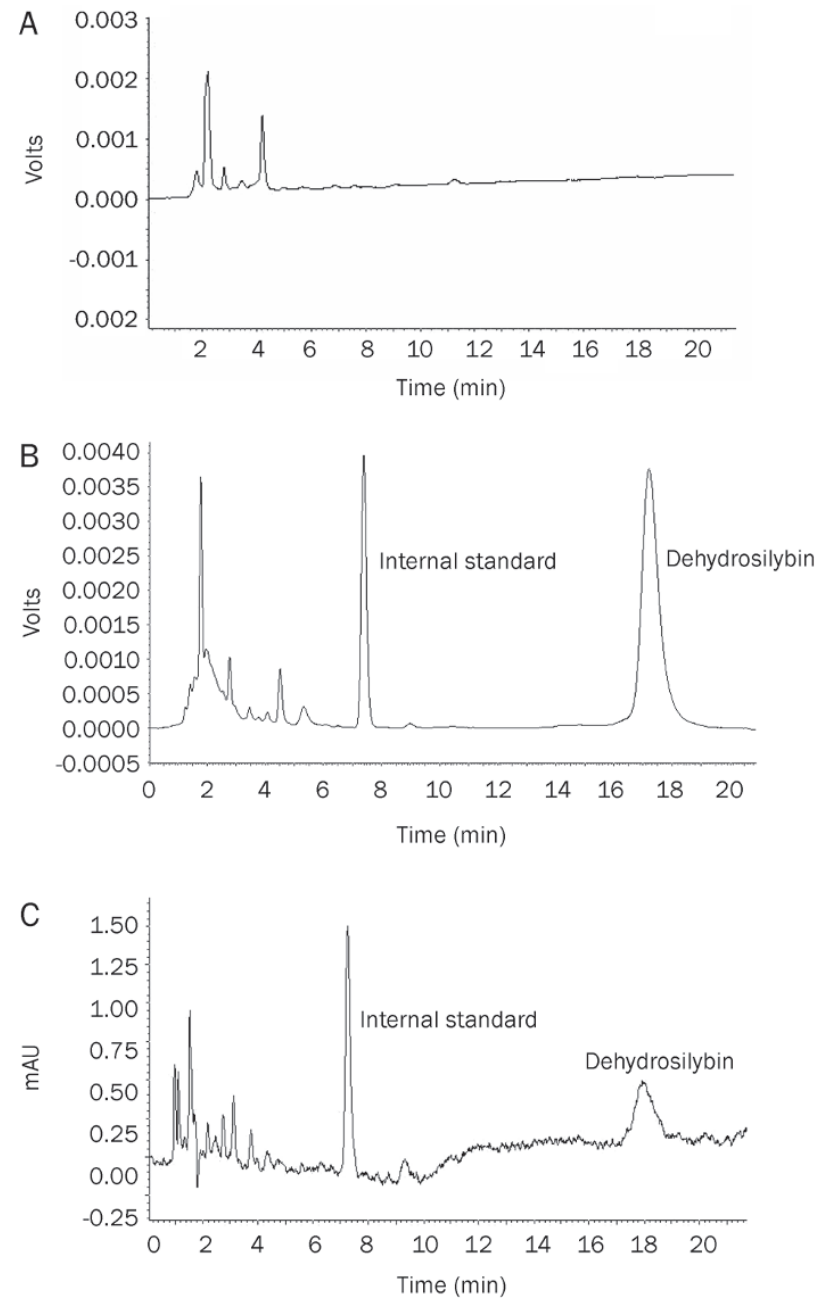

Figure 4. Typical chromatograms of dehydrosilybin: (A) blank rabbit plasma; (B) blank rabbit plasma spiked with dehydrosilybin; (C) a sample after oral administration of dehydrosilymarin-loaded proliposomes.

was much higher than that of dehydrosilymarin suspension at every time point, and doubly sharp peaks at maximum concentrations were seen as a result, which is a characteristic of enterohepatic circulation ${ }^{[24]}$. Moreover, $C_{\max }$ was approximately $0.57 \mathrm{\mu g} / \mathrm{mL}$ after the dehydrosilymarin suspension was orally administered to rabbits with a $t_{\max }$ of $2.00 \mathrm{~h}$. Meanwhile, after oral administration of the dehydrosilymarinloaded liposomal suspension, the value of $C_{\max }$ was approximately $2.83 \mathrm{\mu g} / \mathrm{mL}$ with a $t_{\max }$ of $0.50 \mathrm{~h}$. In conclusion, the dehydrosilymarin-loaded proliposomes took less time to reach

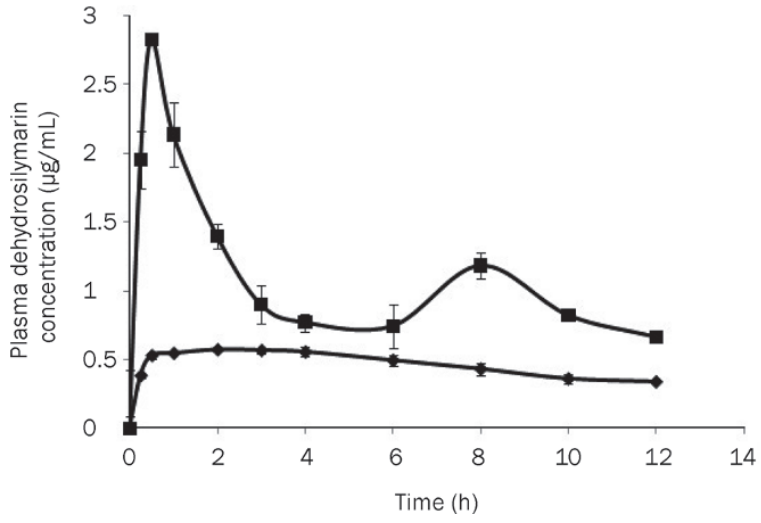

Figure 5. Mean plasma concentration-time curves of dehydrosilybin after oral administration of dehydrosilymarin suspension and dehydrosilymarinloaded liposomal suspension ( $n=3,80 \mathrm{mg} / \mathrm{kg}$ ). ( $\downarrow$ ), dehydrosilymarin suspension; (๘), dehydrosilymarin-loaded liposomal suspension. Data expressed as mean \pm SD.

the maximum plasma concentration in comparison with the dehydrosilymarin suspension, and the $C_{\max }$ was approximately 4.96-fold higher than that of the dehydrosilymarin suspension.

The pharmacokinetic parameters calculated by the software program BAPP 2.3 are shown in Table 2. It was found that the curves plotting the plasma concentration of dehydrosilybin over time after the oral administration of the dehydrosilymarin suspension and dehydrosilymarin-loaded liposomal suspension in rabbits were both in accordance with a noncompartment model. As shown in Table 2, dehydrosilymarinloaded proliposomes exhibited higher absorption in $12 \mathrm{~h}$. The $\mathrm{AUC}_{\mathrm{t}}$ of the vesicle was approximately 2.29-fold higher than that of the dehydrosilymarin suspension, which meant that the relative bioavailability of dehydrosilymarin-loaded proliposomes was approximately $228.85 \%$.

Table 2. Pharmacokinetic parameters of dehydrosilymarin suspension and dehydrosilymarin-loaded liposomal suspension ( $n=3,80 \mathrm{mg} / \mathrm{kg}$ ). Data expressed as mean \pm SD.

\begin{tabular}{lccc}
\hline Parameters & Unit & Dehydrosilymarin & $\begin{array}{c}\text { Dehydrosilymarin-loaded } \\
\text { proliposomes }\end{array}$ \\
\hline $\mathrm{AUC}_{\mathrm{t}}$ & $\mu \mathrm{g} \cdot \mathrm{mL}^{-1} \cdot \mathrm{h}$ & $5.58 \pm 0.21$ & $12.77 \pm 1.39$ \\
$t_{1 / 2}$ & $\mathrm{~h}$ & $20.63 \pm 5.03$ & $7.48 \pm 0.30$ \\
$t_{\max }$ & $\mathrm{h}$ & 2.00 & 0.50 \\
$\mathrm{MRT}$ & $\mathrm{h}$ & $21.33 \pm 0.24$ & $6.98 \pm 0.71$ \\
\hline
\end{tabular}

Table 1. The precision and recovery tests of dehydrosilybin in rabbit plasma. Data expressed as mean \pm SD. $n=5$.

\begin{tabular}{rrrrrr}
\hline $\begin{array}{c}\text { Added } \\
(\mu \mathrm{g} / \mathrm{mL})\end{array}$ & Within-day & \multicolumn{2}{c}{ Between-day } \\
\hline 1.0 & Concentration $(\mu \mathrm{g} / \mathrm{mL})$ & RSD $(\%)$ & Concentration $(\mu \mathrm{g} / \mathrm{mL})$ & RSD $(\%)$ \\
5.0 & $1.02 \pm 0.10$ & 10.21 & $1.22 \pm 0.17$ & 14.22 & 121.8 \\
50.0 & $5.49 \pm 0.03$ & 0.51 & $5.84 \pm 0.60$ & 10.34 & 8.79 \\
\hline
\end{tabular}




\section{In vitro and in vivo correlation}

The in vitro and in vivo correlation was analyzed using the software program BAPP 2.3. The Wegner-Nelson method was applied to compare the in vitro drug release curve with the in vivo absorption curve. The linear regression equations of drug powders and proliposomes in vivo versus release percentages in vitro after 1-12 h were calculated. As presented in Table 3, $\mathrm{F}_{\mathrm{r}}$ was the in vitro release percentage, and $\mathrm{F}_{\mathrm{a}}$ was the in vivo absorption percentage. Apparently, the in vivo absorption of dehydrosilymarin and proliposomes significantly correlated with the in vitro drug release at both $\mathrm{pH} 1.2$ and $\mathrm{pH}$ 6.8; the in vitro release study could be used to help predict the drug absorption in vivo.

\section{Discussion}

Silymarin is a flavonoid complex extracted from seeds of the milk thistle (Silybum marianum) ${ }^{[25]}$ that contains the main active compounds silybin, silychristine and silydianin ${ }^{[2]}$. Silybin, the major active moiety, has been widely used in the prevention and treatment of various liver diseases. Nevertheless, the bioavailability of silybin is rather limited due to its low solubility in water ${ }^{[26,27]}$. The equilibrium solubility of silybin in water is approximately $51.06 \mu \mathrm{g} / \mathrm{mL}$ at $37^{\circ} \mathrm{C}$. Therefore, some preparations have been made in recent years to improve the solubility and bioavailability of silybin, including phospholipid complexes $^{[28]}$, sodium cholate/phospholipid complexes and povidone-sodium cholate-phospholipid mixed micelles ${ }^{[29,30]}$. Recently, 2,3-dehydrosilybin, an oxidized form of silybin, has been reported to exhibit a significantly greater antioxidant and anticancer activity in comparison with silybin ${ }^{[22]}$. We synthesized dehydrosilymarin following the method originally designed for the preparation of dehydrosilybin and confirmed that dehydrosilymarin showed increased antiradical and antioxidative capacities than those of silybin, dehydrosilybin and silymarin ${ }^{[5]}$. The compositions of dehydrosilymarin were studied with HPLC-MS analysis (data not shown).

Prior to the preparation of proliposomes, we initially produced dehydrosilymarin-phospholipid complexes to improve the lipid solubility of dehydrosilymarin, which was convenient for the formation of liposomes. The results revealed that the mass ratio of dehydrosilymarin to phospholipid had the most significant effect on entrapment efficiency of proliposomes. With an increasing amount of phospholipid, the encapsulation efficiency of proliposomes was correspondingly increased. When the concentration of phospholipid reached a certain proportion, the encapsulation efficiency of proliposomes was mostly unchanged. Moreover, too high a concentration of phospholipid drastically decreased the drug loading percentage, and gradually increased the viscosity of the final preparation. As a result, optimal drug-lipid ratio was determined to be $1: 3$.

The cumulative release of dehydrosilymarin from proliposomes in $\mathrm{pH} 6.8$ and $\mathrm{pH} 1.2$ was compared to simulate the environment of the stomach and small intestine. Above all, it was important to disperse proliposomes with water to form a liposomal suspension; otherwise, the proliposomes powders would stick to the dialysis bag, thus affecting drug release from the liposomal suspension.

To simulate the in vivo release profiles of the vesicles, minute amounts of surfactant are typically incorporated into the release medium. In this study, $0.1 \%$ sodium dodecyl sulfate was employed as a surfactant, mimicking the presence of bile salts, which are the natural surfactants in the gastrointestinal tract.

The in vitro study showed that the release of dehydrosilymarin from proliposomes in $\mathrm{pH} 1.2$ was relatively poor and that the drug was continuously released from proliposomes in $\mathrm{pH}$ 6.8. These results might be explained by the fact that the lipophilic drug was held by the small fragment of the liposomal membrane. Therefore, the drug that was loaded in the lipid membrane was released mainly through dissolution and diffusion from the lipid bilayer, which could decrease the release rate of dehydrosilymarin from proliposomes ${ }^{[31,32]}$. However, the higher accumulative release ratio of proliposomes in $\mathrm{pH} 6.8$ was attributed to the fact that the formulation afforded a greater solubilizing effect on the drug, thus enhancing the release rate.

A study on the pharmacokinetics of dehydrosilymarinloaded proliposomes in rabbits after oral administration was also conducted. The results indicated that, in rabbits, the absorption profile of the proliposomes was much better than that from the suspension. We speculated that the underlying

Table 3. The correlative results of dehydrosilymarin powders and dehydrosilymarin-loaded proliposomes in vitro and in vivo (Checked the critical value table for $r$, when the degree of freedom $v$ was 8 , critical value $r_{8,0.05}=0.632$, which showed the correlation coefficients of regression equations of drugs $\left.r>r_{8,0.05}\right)$.

\begin{tabular}{|c|c|c|c|c|c|c|c|c|c|c|c|c|}
\hline Formulation type & $t(\mathrm{~h})$ & 0.25 & 0.5 & 1 & 2 & 3 & 4 & 6 & 8 & 10 & 12 & $r$ \\
\hline Powders & $\mathrm{F}_{\mathrm{r}}(\%)$ & 3.67 & 5.81 & 9.58 & 11.73 & 13.76 & 15.22 & 16.31 & 18.24 & 19.67 & 20.17 & 0.9886 \\
\hline in $\mathrm{pH} 1.2$ & $\mathrm{~F}_{\mathrm{a}}(\%)$ & 41.59 & 58.40 & 63.18 & 72.34 & 78.32 & 83.56 & 89.04 & 92.90 & 94.36 & 100.0 & \\
\hline Proliposomes & $\mathrm{F}_{\mathrm{r}}(\%)$ & 2.30 & 2.40 & 2.51 & 2.67 & 3.19 & 3.71 & 3.85 & 4.38 & 4.46 & 5.22 & 0.9594 \\
\hline in $\mathrm{pH} 1.2$ & $\mathrm{~F}_{\mathrm{a}}(\%)$ & 25.33 & 40.12 & 40.76 & 44.57 & 46.84 & 51.29 & 61.89 & 81.08 & 91.19 & 100.0 & \\
\hline Powders & $\mathrm{F}_{\mathrm{r}}(\%)$ & 4.81 & 5.61 & 7.99 & 12.46 & 19.96 & 26.15 & 33.00 & 40.83 & 44.66 & 48.04 & 0.9362 \\
\hline in $\mathrm{pH} 6.8$ & $\mathrm{~F}_{\mathrm{a}}(\%)$ & 25.33 & 40.12 & 40.76 & 44.57 & 46.84 & 51.29 & 61.89 & 81.08 & 91.19 & 100.0 & \\
\hline
\end{tabular}


mechanism for the improvement of oral absorption of proliposomes could be explained by the relatively small size of the proliposomes, the presence of bile salts and the similarity between liposomal lipid bilayers and biomembranes. Therefore, we deduced that proliposomes, as a new dosage form, provide a promising method to enhance the oral absorption of hydrophobic drugs. As noted in the results, the double peak phenomenon was observed for the plasma concentration versus time curve for dehydrosilymarin-loaded proliposomes. Enterohepatic cycling is known to be responsible for secondary peaks in relation with bile salts, the component of proliposomes.

Interestingly, although the plasma concentration of the dehydrosilymarin suspension was low, the MRT was relatively long (about $21.33 \mathrm{~h}$ after oral administration). However, we failed to detect the existence of the drug after oral administration of the same dosage of silymarin, which meant that the absorption of dehydrosilymarin in vivo was obviously better than silymarin. The reasons that dehydrosilymarin exhibited better bioavailability will be investigated in our further research.

In summary, the current study demonstrates that the oral bioavailability of the new drug dehydrosilymarin was significantly enhanced by proliposomes (a polyphase dispersed system composed of phospholipids, cholesterol, isopropyl myristate, and sodium cholate). The relatively small size of proliposomes, the presence of bile salts and the similarity between liposomal lipid bilayers and biomembranes might be responsible for the improved oral absorption. Moreover, the results in vivo significantly correspond with the in vitro release results, suggesting that the in vitro release study can be used to help predict drug absorption in vivo. However, the absorption mechanism of dehydrosilymarin will require further investigation.

\section{Acknowledgements}

This work was supported by the National Natural Science Foundation of China (No 30973677 and 30472098) and the Natural Science Fund from Jiangsu Municipal Government, Jiangsu, China (№ 08KJB360001).

\section{Author contribution}

Xi-ming XU, Jiang-nan YU, and Yan-ru GE designed the research; Shan-shan TONG and Chang CHU performed the research; Xi-ming XU, Shan-shan TONG, Ying XU, Li WANG, Chang $\mathrm{CHU}$, and Min FU analyzed the data; Chang $\mathrm{CHU}$ wrote the paper.

\section{References}

1 Weiss R, Fintelmann V. Herbal Medicine, 2nd ed. Thieme, Stuttgart, New York, 2000. p 109-11.

2 Schuppan D, Jia JD, Brinkhaus B, Hahn EG. Herbal products for liver diseases: a therapeutic challenge for the new millennium. Hepatology 1999; 30: 99-104.

3 Wu W, Wang Y, Que L. Enhanced bioavailability of silymarin by selfmicroemulsifying drug delivery system. Eur J Pharm Biopharm 2006;
63: 288-94.

4 Xiao YY, Song YM, Chen ZP, Ping QN. Preparation of silymarin proliposome: a new way to increase oral bioavailability of silymarin beagle dogs. Int J Pharm 2006; 319: 162-8.

5 Tong SS, Chu C, Wei Y, Wang L, Gao XZ, Xu XM, et al. Preparation and effects of 2,3-dehydrosilymarin, a promising and potent antioxidant and free radical scavenger. J Pharm Pharmacol 2011; 63: 238-44.

6 Chen YP, Lu Y, Chen JM, Lai J, Sun J, Hu FQ, et al. Enhanced bioavailability of the poorly water-soluble drug fenofibrate by using liposomes containing a bile salt. Int J Pharm 2009; 376: 153-60.

7 Ariën A, Goigoux C, Baquey C, Dupuy B. Study of in vitro and in vivo stability of liposomes loaded with calcitonin or indium in the gastrointestinal tract. Life Sci 1993; 53: 1279-90.

8 Ariën A, Henry-Toulmé N, Dupuy B. Calcitonin-loaded liposomes: stability under acidic conditions and bile salts-induced disruption resulting in calcitonin-phospholipid complex formation. Biochim Biophys Acta 1994; 1193: 93-100.

9 Aungust BJ. Novel formulation strategies for improving oral bioavailability of drugs with poor membrane permeation or presystemic metabolism. J Pharm Sci 1993; 82: 979-87.

10 Sivakumar PA, Panduranga Rao K. The use of cholesteryl pullulan for the preparation of stable vincristine liposomes. Carbohydr Polym 2003; 51: 327-32.

11 Lau KG, Hattori Y, Chopra S, O'Toole EA, Storey A, Nagai T, et al. Ultradeformable liposomes containing bleomycin: in vitro stability and toxicity on human cutaneous keratinocyte cell lines. Int J Pharm 2005; 300: 4-12.

12 Cocera M, Lopez O, Coderch L, Parra JL, de la Maza A. Permeability investigations of phospholipid liposomes by adding cholesterol. Colloids Surf A Physicochem Eng Asp 2003; 221: 9-17.

13 Dong C, Rogers JA. Polymer-coated liposomes: stability and release of ASA from carboxymethyl chitin coated liposomes. J Control Release 1991; 17: 217-24.

14 Henriksen I, Vhgen SR, Sande SA, Smistad G, Karlsen J. Interactions between liposomes and chitosan. II. Effect of selected parameters on aggregation and leakage. Int J Pharm 1997; 146: 193-204.

15 Takeuchi H, Kojima H, Yamamoto H, Kawashima Y. Evaluation of circulation profiles of liposomes coated with hydrophilic polymers having different molecular weights in rats. J Control Release 2001; 75: 83-91.

16 Guo J, Ping Q, Jiang G, Huang L, Tong Y. Chitosancoated liposomes: characterization and interaction with leuprolide. Int J Pharm 2003; 260: 167-73.

17 Winden E, Crommelin D. Short term stability of freeze-dried, lyoprotected liposomes. J Control Release 1999; 58: 69-86.

18 Glavas-Dodov M, Fredro-Kumbaradzi E, Goracinova K, Simonoska M, Calis S, Trajkovic-Jolevska S, et al. The effects of lyophilization on the stability of liposomes containing 5-FU. Int J Pharm 2005; 291: 79-86.

19 Sweeney LG, Wang Z, Loebenberg R, Wong JP, Lange CF, Finlay WH. Spray-freeze-dried liposomal ciprofloxacin powder for inhaled aerosold rug delivery. Int J Pharm 2005; 305: 180-5.

20 Hildebrand A, Beyer K, Neubert R, Garidel P, Blume A. Temperature dependence of the interaction of cholate and deoxycholate with fluid model membranes and their solubilization into mixed micelles. Colloids Surf B Biointerfaces 2003; 32: 335-51.

21 Porter CJ, Trevaskis NL, Charman WN. Lipid and lipid-based formulations: optimizing the oral delivery of lipophilic drugs. Nat Rev Drug Discov 2007; 6: 231-48.

22 Gazák R, Svobodová A, Psotová J, Sedmera P, Prikrylová V, Walterová $\mathrm{D}$, et al. Oxidised derivatives of silybin and their antiradical and anti- 
oxidant activity. Bioorg Med Chem 2004; 12: 5677-87.

23 Takemoto T, Ikegawa S, Nomoto K. Studies on constituents of Silybum marianum (L) Gaertn. I. New flavonolignans named 2,3-dehydrosilymarin and 2,3-dehydrosilychristin. Yakugaku Zasshi 1975; 95 : 1017-21.

24 Morazzoni P, Montalbetti A, Malandrino S, Pifferi G. Comparative pharmacokinetics of silipide and silymarin in rats. Eur J Drug Metab Pharmacokinet 1993; 18: 289-97.

25 Luper S. A review of plants used in the treatment of liver disease: part 1. Altern Med Rev 1998; 3: 410-21.

26 Křen V, Walterova D. Silybin and silymarin-new effects and applications. Biomed Pap Med Fac Univ Palacky Olomouc Czech Repub 2005; 149: 29-41.

27 Gažák R, Walterová D, Křen V. Silybin and silymarin-new and emerging applications in medicine. Curr Med Chem 2007; 14: 315-38.

28 Xiao YY, Song YM, Chen ZP, Ping QN. The preparation of silybinphospholipid complex and the study on its pharmacokinetics in rats.
Int J Pharm 2006; 307: 77-82.

29 Yu JN, Zhu Y, Wang L, Peng M, Tong SS, Cao X, et al. Enhancement of oral bioavailability of the poorly water-soluble drug silybin by sodium cholate/phospholipid-mixed micelles. Acta Pharmacol Sin 2010; 31: 759-64.

30 Zhu Y, Yu JN, Tong SS, Wang L, Peng M, Cao X, et al. Preparation and in vitro evaluation of povidone-sodium cholate-phospholipid mixed micelles for the solubilization of poorly soluble drugs. Arch Pharm Res 2010; 33: 911-7.

31 Cocera M, Lopez O, Coderch L. Alterations in stratum corneum lipid liposomes due to the action of Triton X-100: influence of the level of ceramides on this process. J Control Release 2000; 68: 387-96.

32 Du B, Li Y, Li XT, A YM, Chen CQ, Zhang ZZ. Preparation, characterization and in vivo evaluation of 2-methoxyestradiol-loaded liposomes. Int J Pharm 2010; 384: 140-7. 